\title{
IMPROVING DOCTOR-NURSE COMMUNICATION BY SITUATION, BACKGROUND, ASSESMENT, AND RECOMMENDATION
}

\author{
Catur Septi Asih, Fitri Arofiati, Elsye Maria Rosa \\ Masters Program in Hospital Management, \\ Universitas Muhammadiyah Yogyakarta
}

\begin{abstract}
Background: Patient safety is the absence of preventable harm to a patient during the process of health care and reduction of risk of unnecessary harm associated with health care to an acceptable minimum. Patient safety can be improved with better communication between health worker and patient. An effective communication technique commonly used in health service was situation-background-assessment-recommendation (SBAR). The purpose of this study was to explore SBAR in improving doctor-nurse communication in the hospital.

Subjects and Method: This was a qualitative study with action research. The study was conducted in 2 stages. First stage included: (1) planning (pre-study observation); (2) action (training and observation during training); and (3) reflection (receive feedback, plan improvement, and develop focus group discussion). The second stage was implementing focus group discussion. The evaluation was done by comparing the results from both stages.

Results: Nurse and doctor have understood SBAR method. They were able to practice SBAR communication method after training. Communication barriers among nurse and doctor in implementing SBAR method arose from the differences in: (1) perception, (2) value, (3) culture, (4) knowledge, (5) role, and (6) location of interaction.

Conclusion: Training can improve nurse and doctor knowledge and skill in implementing SBAR communication method. There is a need to reduce barrier in conducting SBAR among nurse and doctor.
\end{abstract}

Keywords: effective communication, SBAR, health worker

\section{Correspondence:}

Catur Septi Asih. Masters Program in Hospital Management, Universitas Muhammadiyah Yogyakarta. Jl. Brawijaya, Bantul, Yogyakarta 55183, Indonesia. Email: catoer.asih@yahoo.com. Mobile: 081328667650. 